\title{
Representasi Maskulinitas Pria dalam Iklan Televisi Men's Biore Cool Oil Clear
}

\author{
Rezki Pratami* \\ Togi Prima Hasiholan \\ Magister Ilmu Komunikasi, Universitas Budi Luhur, Jakarta Selatan, Indonesia \\ Email:rezkypratami@gmail.com
}

\begin{abstract}
The purpose of this research is to analyze the meaning contained in Men's Biore Cool Oil Clear advertisement in three different versions namely version \#BeMagnetic 2019, \#RefreshSangatLo! 2018, and Long Riding 2017, and discuss the myths and male masculinity representation by using Roland Barthes's semiotic theory. The results showed that the three ads represent men into 8 myths, namely Men as free creatures, Men as good-looking creatures, Men as charismatic creatures, Men as leaders, Men as optimistic beings, Men as rulers, and Men as narcissist beings. The masculine traits contained are Give em Hell, Metrosexual, Be a Big Wheel, Be a Sturdy Oak, and New man as narcissist. The message of masculinity formed is an easy way to wash face to be able to become a masculine, namely men who pay attention to cleanliness and appearance of themselves, which opens new perspectives in the wider community over the stereotypes of masculine images that have been circulating.
\end{abstract}

Keywords: Representation, Masculinity, Semiotics, Advertising, Men's Biore Cool Oil Clear.

\begin{abstract}
Abstrak. Tujuan penelitian adalah menganalisis makna yang terkandung dalam iklan Men's Biore Cool Oil Clear dalam tiga versi berbeda yaitu versi \#BeMagnetic 2019, \#RefreshSemangatLo! 2018, dan Long Riding 2017, serta membahas mitos dan representasi maskulinitas pria dengan menggunakan teori semiotika Roland Barthes. Hasil penelitian menunjukkan bahwa ketiga iklan tersebut merepresentasikan pria kedalam 8 mitos, yaitu Pria sebagai makhluk bebas, Pria sebagai makhluk rupawan, Pria sebagai makhluk kharismatik, Pria sebagai pemimpin, Pria sebagai makhluk optimis, Pria sebagai makhluk penguasa, dan Pria sebagai makhluk narcissist.. Sifat-sifat maskulin yang terkandung adalah Give em Hell, Metroseksual, Be a Big Wheel, Be a Sturdy Oak, dan New man as narcissist. Pesan maskulinitas yang dibentuk adalah cara mudah mencuci muka agar menjadi maskulin, yakni pria yang memperhatikan kebersihan dan penampilan diri sendiri. Suatu sudut pandang baru di masyarakat luas terkait maskulin.
\end{abstract}

Kata Kunci: Representasi, Maskulinitas, Semiotika, Iklan, Men’s Biore Cool Oil Clear.

*Penulis Korespondensi 


\section{PENDAHULUAN}

Di era pos industrial, perusahaan beberapa merek mencoba mencari pangsa pasar yang baru untuk dijadikan subjek dalam beriklan. Tak sedikit yang beralih kepada kaum pria untuk dijadikan sebagai komoditinya. Hingga akhir 1990-an, pasar terbesar terpusat pada pria, yang melahirkan tren baru yakni urusan penampilan bagi pria (Kusumaningrum, 2012).

Ideologi tentang maskulin bagi pria menjadi hal yang perlu diperhitungkan dalam kebutuhan hidup. Alih-alih agar terlihat maskulin dan macho, seorang pria kini rela merombak dirinya agar terlihat lebih trendi, sama halnya dengan wanita yang ingin terlihat cantik. Kata maskulin cukup bisa mewakili kesempurnaan pria baik dari segi penampilan maupun inner beauty pria.

Yuliyanti et al., (2017) memaparkan pengertian maskulin sebagai sifat ideal yang lekat dengan laki-laki yang terbentuk dari budaya. Runtiko (Runtiko, 2011) menjelaskan norma dan nilai - nilai hingga menjadi budaya mengenai pria tumbuh dari ruang lingkup masyarakat itu sendiri sehingga terjadi secara turun temurun dan terus berkembang meskipun mengalami redefinisi, rekonstruksi, dan dekonstruksi dalam proses perkembangan sosialnya.

Smiler (2004) dalam Tanjung, (2012) menjelaskan istilah maskulin berasal dari bahasa inggris, yakni muscle yang dalam bahasa Indonesia berarti otot. Maksud maskulin di sini, yaitu sifat yang didasari pada kekuatan fisik atau otot yang diimplikasikan sebagai hal yang kuat. Istilah tersebut akhirnya dikaitkan kepada pria karena dinilai sebagai makhluk yang memiliki kekuatan fisik lebih kuat dibandingkan perempuan.
Dalam buku Budaya Populer Sebagai Komunikasi Dinamika Popscape dan Mediascape di Indonesia Kontemporer, Ibrahim (2007) menjelaskan bahwa maskulinitas dipandang sebagai sesuatu yang terbentuk sebagai hasil dari konstruksi sosial. Laki-laki dapat dianggap sebagai sosok yang maskulin tergantung berbagai faktor penentu seperti ideologi, ekonomi, poitik, etnik, agama, sosial budaya, golongan, adat istiadat, sejarah hingga kemajuan teknologi dan pengetahuan.

Konstruksi sosial mengenai ideologi maskulin juga didukung media sebagai medium penyampaian pesan. Media kerap kali menampilkan sisi kejantanan seorang pria lewat ilustrasi pada iklan yang menyasar target pasar dan para calon konsumen ideal. Sebagai contoh, iklan produk minuman digambarkan dalam adegan pria berotot yang menjadi dambaan wanita, ada pula iklan beberapa merek produk rokok yang kerap menampilkan seorang pria dalam pembawaan yang berani, tangkas, berani menantang maut, berwibawa, macho, juga sensitif (Bungin, 2011).

Dalam kajian ilmu sosiologi mengenai gender oleh Connel (dalam Wajcman, 2001), terdapat dua bentuk maskulinitas, yakni maskulinitas yang terbentuk secara budaya (maskulinitas hegemonik) dan maskulinitas yang tersubordinari. Maskulinitas hegemonik, yaitu maskulinitas yang terpengaruh oleh keadaan sosial yang memenuhi proses budaya.

David dan Brannon dalam Demartoto (2010) memaparkan sifat-sifat maskulinitas dalam delapan kelompok, yakni no sissy stuff, be a big wheel, be a sturdy oak, give em hell, new man as nurturer, new man as narcissist, macho dan hologanism, serta metroseksual. 
Jannah \& Kusumawati (2016), memaparkan bahwa saat ini terjadi pergeseran makna maskulin karena maskulin sudah merambah ke area feminin. Era globalisasi menyebabkan konstruksi diri pria mengalami adaptasi yang dikenal dengan sebutan new masculinity.

Mengutip pernyataan Mark Simpson (2002) (dalam Triwidiastuty \& Kahija, 2015), pergeseran ideologi maskulin dalam konstruksi new masculinity disebut juga dengan istilah metroseksual. Mark adalah seorang fashion kolumnis yang membuat istilah metroseksual mencuat ke permukaan media massa, lewat buku yang berjudul "Male Impersonator: Men Performing Masculinity", yang mengartikan Metroseksual sebagai 'a dandy is narcissist in love with not only himself but also his urban lifestyle', yang berarti sosok narsistik berpenampilan dandy yang cinta pada dirinya sendiri dan gaya hidup urban.

Flocker, (2003) memaparkan pengertian metroseksual, yakni "the typical metrosexual is a young man with money to spend, living in or within easy reach of a metropolis-because that where all the best shops, clubs, gyms, and hairdresser are". Ini berarti metroseksual adalah tipe laki-laki muda dengan simpanan uang dan tinggal di kota metropolis karena disanalah mereka bisa dengan mudah menemukan pusat perbelanjaan, klub, pusat kebugaran, dan penata rambut.

Kartajaya (2006) menyebutkan bahwa secara umum di Indonesia pria metroseksual telah tumbuh meskipun secara jumlah belum menunjukkan angka yang signifikan dibandingkan dengan jumlah populasi pria itu sendiri. Mereka umumnya memiliki ciri yang khas, yakni sangat memperhatikan pernampilan, menganut paham kesetaraan gender, memiliki kebisaan bersosialisasi, menganut paham bebas, narsis atau memuja diri sendiri.

Penelitian yang dilakukan oleh perusahaan pemasaran J. Walter Thompson dengan tajuk "The State of Men" menyebutkan bahwa 54\% pria saat ini dengan teratur menggunakan produk perawatan yaitu krim pelembab dan krim mata (indonesiaimaji.com:2019). Kantor Worldpanel Indonesia merilis partumbuhan penetrasi segmen personal care pria lebih tinggi dibanding wanita pada 2016. Berdasarkan jenis produk personal care pria dengan penjualan paling tinggi ada tiga jenis, yaitu shampoo, pembersih wajah dan deodoran.

Aulia Adam (2017) pada artikel "Ledakan Industri Kecantikan Pria", dalam investigasi yang dilakukan oleh Alexander Fury mengatakan bahwa setidaknya industri kosmetik khusus pria secara global mencapai 14,8 miliar pounsterling pada 2016. Grigsby menyebutkan naiknya permintaan akan kosmetik khusus pria disebabkan adanya budaya baru yang dibawa oleh pria berusia muda. Hal ini berdampak pada cerahnya industri kecantikan pria yang diprediksi akan terus naik, tahun 2023 keuntungannya bisa menembus \$27,76 miliar (tirto.id, 2007).

Iklan produk Men's Biore Cool Oil Clear dibuat maksimal dengan memanfaatkan konsep maskulinitas dan keadaan realitas sosial mengenai sosok pria maskulin yang diyakini masyarakat lewat penggambaran lewat kode - kode pada iklan.

Berdasarkan latar belakang di atas, penelitian ini mengkaji makna maskulinitas pria dalam iklan Men's Biore Cool Oil Clear pada tiga versi berbeda yang diproduksi tahun 2017, 2018, dan 2019, yakni versi \#BeMagnetic 2019, \#RefreshSemangatLo! 2018, Dan Long 
Riding 2017 serta membahas mitos dan ideologi representasi maskulinitas pria.

\section{METODE}

Penelitian ini menggunakan pendekatan kualitatif dengan paradigma intepretif. Greetz (dalam Muhadjir, 2000) menjelaskan metode interpretatif merupakan metode yang berusaha mencari arti atau makna dengan berupaya untuk memahami dari subjek yang diteliti dan bukan untuk membuat teori baru.

Rahardjo, (2018) menyebutkan bahwa paradigma interpretatif lahir sebagai bentuk rekasi terhadap paradigma positifis. Reaksi tersebut lahir karena menentang dan mengkritisi paradigma positifis yang dianggap kurang realis dan kurang komprehensif dalam menjelaskan suatu kejadian.

Teknik analisis yang dipilih dalam penelitian ini adalah analisis semiotika karena peneliti akan menganalisis teks berupa simbol ataupun kode yang terkandung dalam iklan Men's Biore Cool Oil Clear dalam 3 versi berbeda yaitu \#BeMagnetic 2019, \#RefreshSemangatLo! 2018 dan versi Long Riding 2017, serta mengetahui konstruksi realitas atas representasi maskulinitas pria pada iklan tersebut.

Mengutip Sobur (dalam Rahayu \& Afrianto, 2017) "Roland Barthes mengungkapkan bahwa bahasa merupakan sebuah sistem tanda yang mencerminkan asumsi - asumsi dari masyarakat tertentu dalam waktu tertentu”. Roland Barthes membagi semiotika dalam 2 hal, yakni denotatif yaitu sistem makna primer, dan konotatif yaitu sistem makna kedua. Rusmana (2014) menyatakan bahwa makna denotasi merupakan makna dari sebuah kata atau sekelompok kata berdasarkan perasaan atau pikiran yang sengaja atau tidak sengaja dimunculkan oleh khalayak (penulis dan pendengar). Makna konotasi, di sisi lain, merupakan makna kata kedua yang bersifat implisit atau tersembunyi.

Asrofah (2014) memaparkan bahwa Mitos Roland Barthes muncul akibat persepsinya akan tanda-tanda misterius yang pada akhirnya menjadi sebuah mitos. Mekanisme kerja mitos dalam suatu ideologi disebutkan Barthes adalah sebagai naturalisasi sejarah. Lebih lanjut, Asrofah menjelaskan mengenai mitos Barthes sebagai "suatu mitos akan menampilkan gambaran dunia yang seolah terjadi begitu saja secara alamiah. Nilai ideologis dari mitos muncul ketika mitos tersebut menyediakan fungsinya untuk mengungkap dan membenarkan nilai-nilai dominan yang ada”.

Penelitian ini juga mengkaji representasi. Menurut Hall dalam (Wibowo \& Wahyu, (2011), ada dua proses dalam representasi, yakni representasi mental yaitu representasi yang berasal dari benak manusia dan berbentuk abstrak, yang kedua adalah bahasa, dimana bahasa merupakan sesuatu yang memegang peranan penting dalam pembentukan proses konstruksi makna. Maksudnya adalah pemikiran abstrak yang muncul dari benak manusia harus diterjemahkan dalam bahasa yang mudah dipahami seseorang, agar mampu menginterpresasikan antara konsep dan gagasan denga tanda atau simbol yang berarti sesuatu. 


\section{HASIL DAN PEMBAHASAN}

Pada bagian ini, peneliti akan memaparkan makna yang terkandung dalam iklan Men's Biore Cool Oil Clear versi \#BeMagnetic 2019,
\#RefreshSemangatLo! 2018, Dan Long Riding 2017. Pada masing - masing iklan yang berdurasi 30 detik, peneliti akan mengambil potongan adegan dan menjabarkan makna yang terkandung di dalam iklan tersebut.
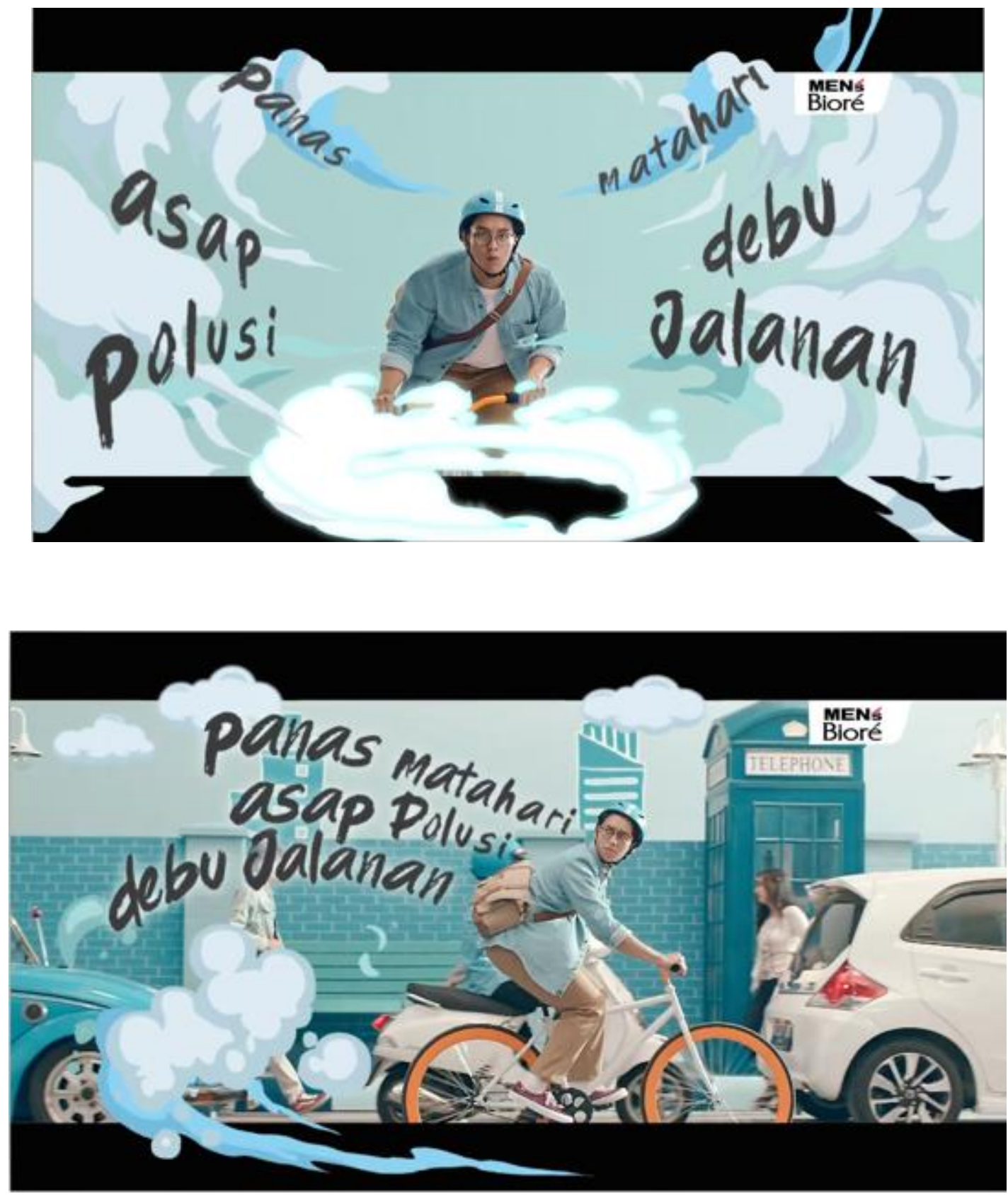

Gambar 1 dan 2. Adegan Pria Bersepeda 
Table 1. Peta Bekerjanya Tanda Pada Adegan 'Pria Bersepeda'

Pada Iklan Men's Biore Cool Oil Clear 2019 \#BeMagnetic

\begin{tabular}{cc}
\hline $\begin{array}{c}\text { Penanda (Denotatif) } \\
\text { Gambar seorang pria menaiki sepeda } \\
\text { dengan mengenakan helm dan berpakaian } \\
\text { casual }\end{array}$ & $\begin{array}{c}\text { Petanda (Denotatif) } \\
\text { Seorang pria menaiki sepeda dengan } \\
\text { mengenakan helm dan berpakaian casual }\end{array}$ \\
\hline Tanda (Denotatif) \\
Seorang pria hendak melakukan perjalanan dengan mengunakan sepeda agar terhindar \\
dari macet
\end{tabular}

\section{Mitos Pria Sebagai Makhluk Bebas}

Adegan pertama menggambarkan seorang pria menaiki sepeda dalam aktifitasnya untuk menerjang kemacetan meski harus melawan panas matahari, debu, kotoran dan polusi yang ada di jalan raya.

Dominasi warna dalam setting dan elemen properti serta wardrobe adalah warna - warna biru dan gradasinya. Warna biru dipilih sebagai identitas warna dari produk biore men's cool oil clear. Warna merupakan elemen yang tidak bisa dikesampingkan dan aspek relatif dalam kehidupan yang diimplementasikan dalam desain.

Persepsi warna pada elemen iklan biore men's cool oil clear melibatkan fisologi manusia dan respon psikologi yang memiliki arti. Secara filosofi, menurut C.S Jones (2015) dalam Hico (2019), warna biru memberikan kesan yang menenangkan karena merangsang pemikiran yang jernih juga meningkatkan konsentrasi. Warna biru juga dikatakan sebagai warna corporate karena banyak perusahaan menggunakan warna biru dalam logo perusahaan. Hal ini karena warna biru dapat memberikan kesan professional dan kepercayaan yang tinggi, simbol kekuatan, ekspresi atristik, dan merangsang komunikasi yang baik pada yang mempercayainya. (goodminds.id, 2019)

Berdasarkan Kamus Besar Bahasa Indonesia, sepeda merupakan "kendaraan beroda dua atau tiga, mempunyai setang, tempat duduk dan sepasang pengayuh yang digerakkan kaki untuk menjalankannya" (KBBI edisi III). Dalam hal ini, sifat maskulinitas dalam mitos representasi pria sebagai makhluk bebas adalah give em hell. Give em hell menunjukkan sifat maskulinitas yang merujuk pada keberanian seorang pria. Seorang pria berani ditunjukkan dengan karakter yang tidak memiliki rasa takut dan berani menanggung segala risiko dengan keputusan yang diambilnya. Keputusan aktor dalam adegan mengendarai sepeda dianggap sebagai pengambilan keputusan yang berani. Dengan demikian, mengendarai sepeda di jalan raya dan diantara kendaraan bermotor disimpulkan sebagai ide dan solusi manusia bebas dalam mencapai tujuan. 

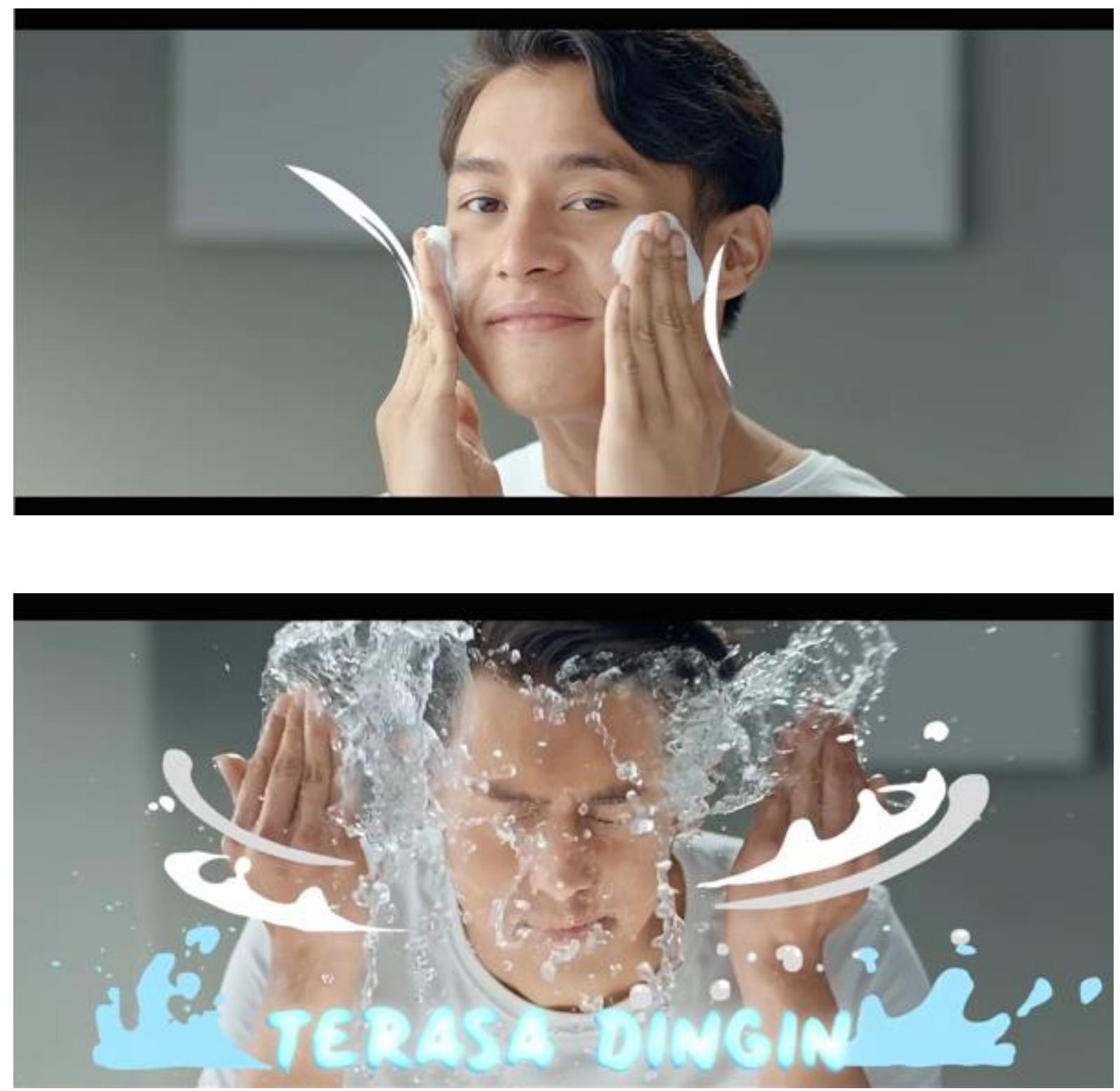

Gambar 3 dan 4. Adegan Mencuci Wajah

Tabel 2. Peta Bekerjanya Tanda Pada Adegan ‘Mencuci Wajah’ Pada Iklan Men’s Biore Cool Oil Clear 2019 \#BeMagnetic

\section{Penanda (Denotatif)}

Gambar seorang pria mencuci wajah

\section{Petanda (Denotatif)}

Seorang pria mencuci wajah

\section{Tanda (Denotatif)}

Seorang pria membersihkan wajah untuk menjaga penampilan

\section{Tanda (Konotasi)}

Kepedulian akan kebersihan dan penampilan

\section{Mitos}

Pria adalah makhluk rupawan 


\section{Mitos Pria Sebagai Makhluk Rupawan}

Adegan di atas menunjukkan bahwa mitos yang direpresentasikan iklan Men's Biore Cool Oir Clear versi \#BeMagnetic 2019 yakni pria adalah makhluk rupawan, yang tergambar pada adegan mencuci muka. Kebersihan merupakan keadaan yang tergolong dalam bebasnya dari kotoran yang dihasilkan oleh lingkungan ataupun perbuatan manusia seperti debu, kotoran, sampah, dan bau (Iskandar, 2018).

Dalam iklan Men's Biore Cool Oir Clear versi \#BeMagnetic 2019 dengan bintang Ardhito Pramono, visualiasinya adalah pria mencuci muka. Dipadukan dengan tulisan pada grafis yakni "terasa dingin" yang menggambarkan bahwa mencuci muka dengan produk Men's Biore Cool Oir Clear akan memberikan sensasi yang dingin dan segar. Pesan yang ingin disampaikan adalah dengan mencuci muka menggunakan produk Biore maka seorang pria akan terlihat menjadi sosok yang rupawan dengan menjaga kebersihan wajahnya. Dalam hal ini, kegiatan mencuci muka dalam adegan iklan Biore Men's Oil Clear direpresentasikan dalam sifat pria metroseksual. Dalam kaitan ini, pria metroseksual selalu memperhatikan setiap penampilannya baik inner beauty dan outer beauty. Salah satu hal yang paling mudah untuk bisa menjaga penampilan adalah dengan cara menjaga kebersihan wajah dengan mencuci muka. Dengan demikian, citra pria sebagai makhluk yang rupawan akan melekat pada dirinya.

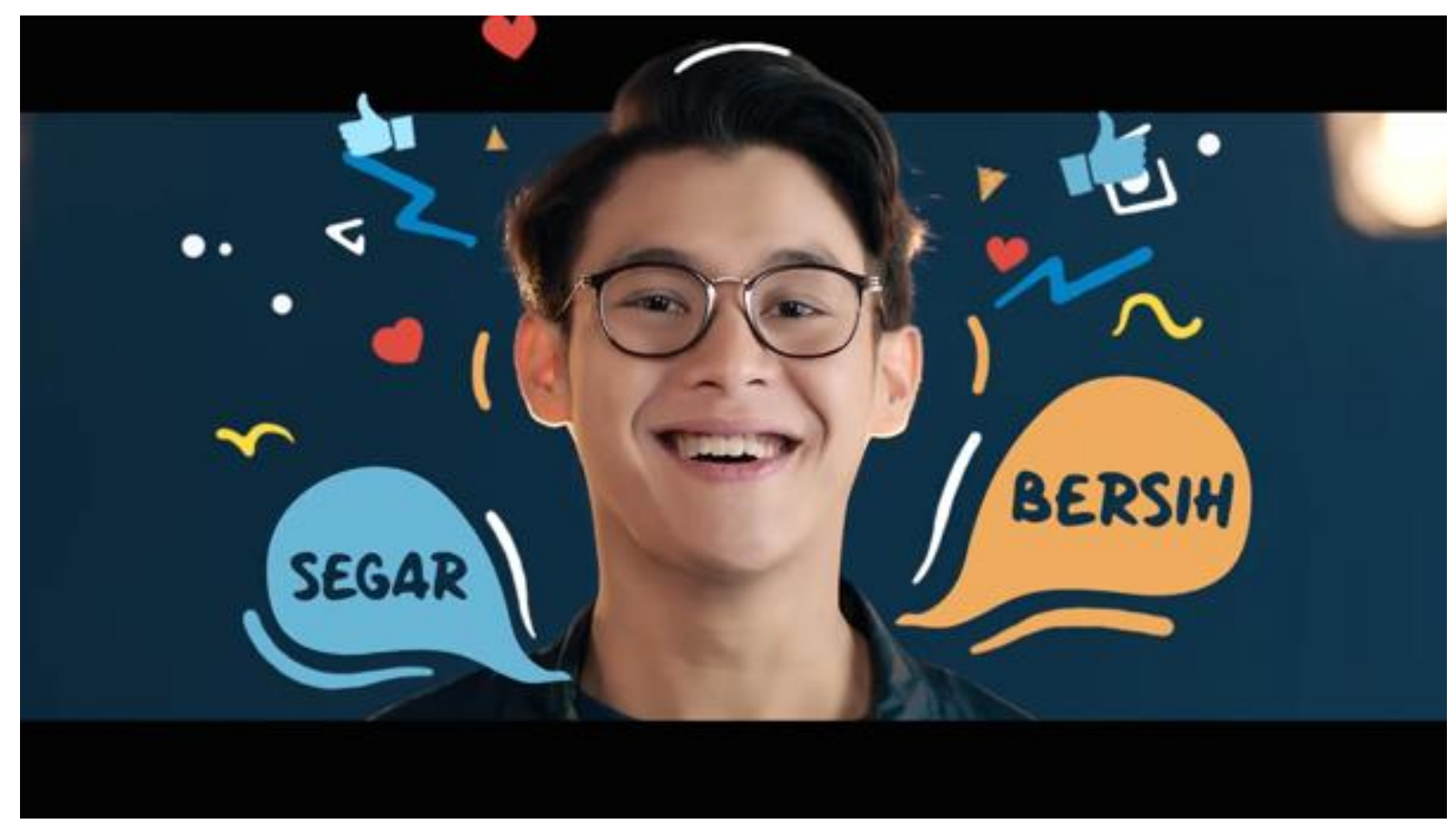



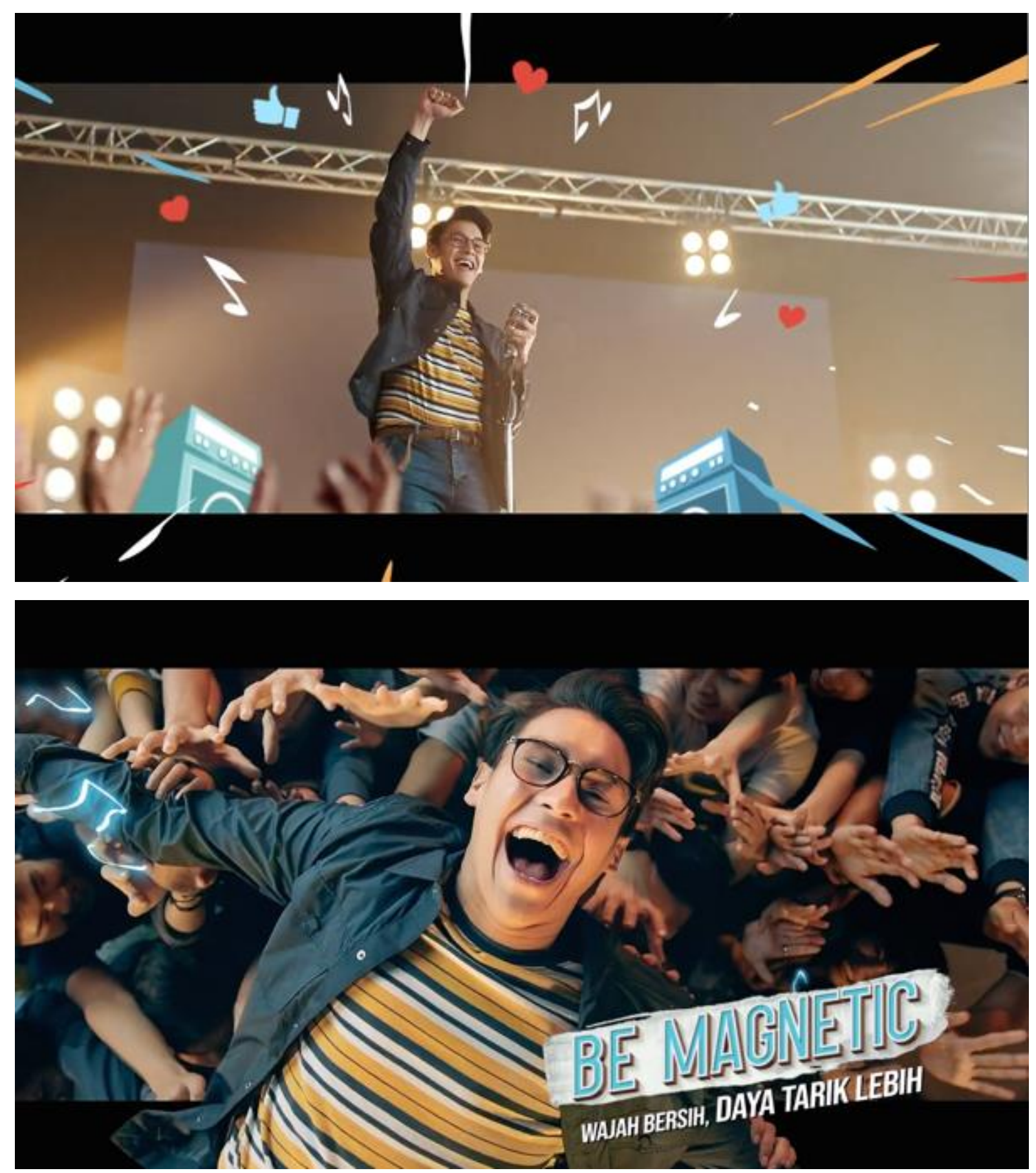

Gambar 5,6,dan 7. Adegan 'Pria Musisi' 
Table 3. Peta Bekerjanya Tanda Pada Adegan 'Pria Musisi’ Pada Iklan Men's Biore Cool Oil Clear 2019 \#BeMagnetic

\begin{tabular}{cc}
\hline $\begin{array}{c}\text { Penanda (Denotatif) } \\
\text { Gambar musisi pria dalam pentas memiliki } \\
\text { banyak penggemar. }\end{array}$ & $\begin{array}{c}\text { Peorang musisi pria dalam pentas yang } \\
\text { memiliki banyak penggemar. }\end{array}$ \\
\hline Teorang musisi pria usai menampilkan pertunjukkan dengan sukses dan disukai \\
penggemarnya \\
\hline Tanda (Konotasi) \\
Pria idola bagi penggemar \\
Mitos \\
Pria adalah makhluk kharismatik
\end{tabular}

\section{Mitos Pria Sebagai Makhluk Kharismatik}

Dalam adegan ini, divisualkan seorang pria yang berprofesi sebagai musisi yang tampak percaya diri diatas pentas dengan penampilan yang nechis, sedap dipandang, dan seraya menunjukkan kharismanya lewat pertunjukkan musik. Dengan bumbu animasi grafis yang memperkuat representasi seorang musisi "segar" dan "bersih" musisi ini nampak percaya diri membawa dirinya dihadapan penggemar.

Terdapat animasi grafis " $B E$ MAGNETIC WAJAH BERSIH DAYA TARIK LEBIH". Pada kata "MAGNETIC" mendeskripsikan musisi tersebut seperti magnet yang mampu menarik hati penggemar. Sosok musisi yang memiliki kharisma baik dari penampilan fisik, cara berpakaian, serta kebisaan lewat aksi panggung menambah poin penggemar untuk mencintainya sebagai idola.

Pria maskulin pada adegan "Pria Musisi” dalam iklan Men's Biore Cool Oir Clear versi \#BeMagnetic 2019 dengan bintang Ardhito Pramono, digambarkan sebagai seorang musisi yang memiliki kharisma. Label "Kharismatik" cukup melekat pada diri pria kelahiran tahun 1995 yang terpilih sebagai finalis top 6 MTV VJ Hunt Indonesia, yang juga memerani tokoh Kale dalam film layar lebar berjudul Nanti Kita Cerita Tentang Hari Ini tahun 2020. Ardhito Pramono yang mulai banyak dikenal sejak 2014 lewat cover lagu yang diunggahnya di media daring Youtube.

Pria yang memiliki karakter kharismatik salah satu indikator adalah memiliki rasa percaya diri yang tinggi, dimata perempuan bahwa pria yang kurang percaya diri bukanlah pria sejati, karena bagi pria memiliki kepercayaan diri dan menerima apa adanya akan menjadi suatu daya tarik bagi lawan jenis (Savitri, 2011).

Wen (2017) dalam laman bbc.com bertajuk "Cara Meguasai Seni Dan Teknik Agar Menjadi Sosok Karismatik", menyebutkan bahwa kharisma meliputi kemampuan berkomunikasi yang baik (verbal, non verbal dan tertulis) dengan menggunakan kalimat perumpamaan anekdot yang kuat, ekspresi, gesture, dalam penyampaian pesan secara emosional yang efektif dengan menunjukkan kepercayaan diri.

Menurut Wahyuningsih (2015), kharisma pria yang dibentuk dalam konteks ini, juga terbentuk dari suara dari pria yang merupakan seorang penampil lewat aksi bernyanyi dan bermain gitar.

Sifat maskulinitas Be a Big Wheel memiliki makna pria sebagai tokoh penting. Menjadi tokoh penting dapat 
dukur dari beberapa aspek seperti kekayaan, kekuasaan, ketenaran, dan dikagumi banyak orang. Dalam adegan ini tergambar sosok pria memiliki ketenaran dan memiliki banyak penggemar sebagai sosok yang kharismatik.
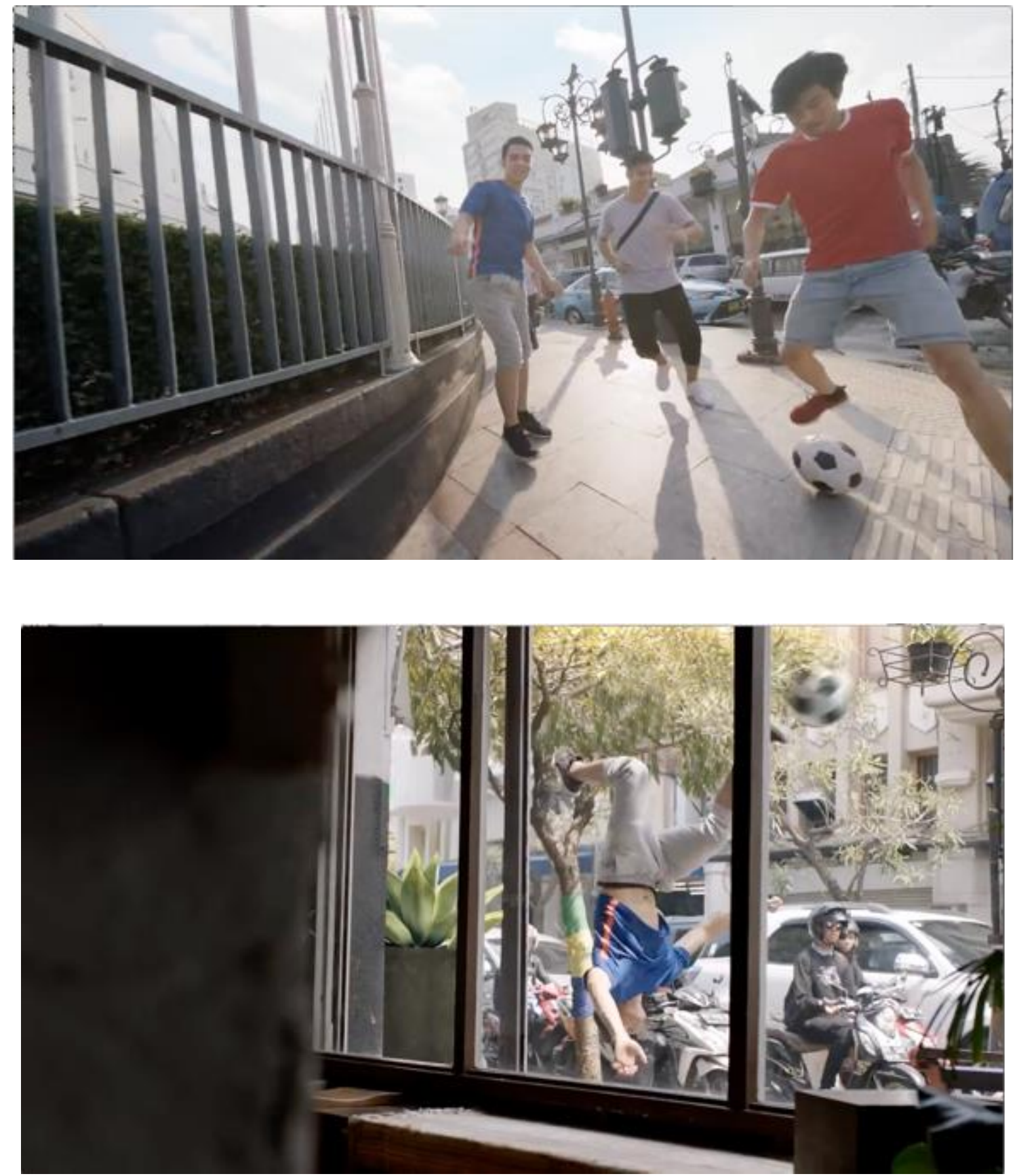


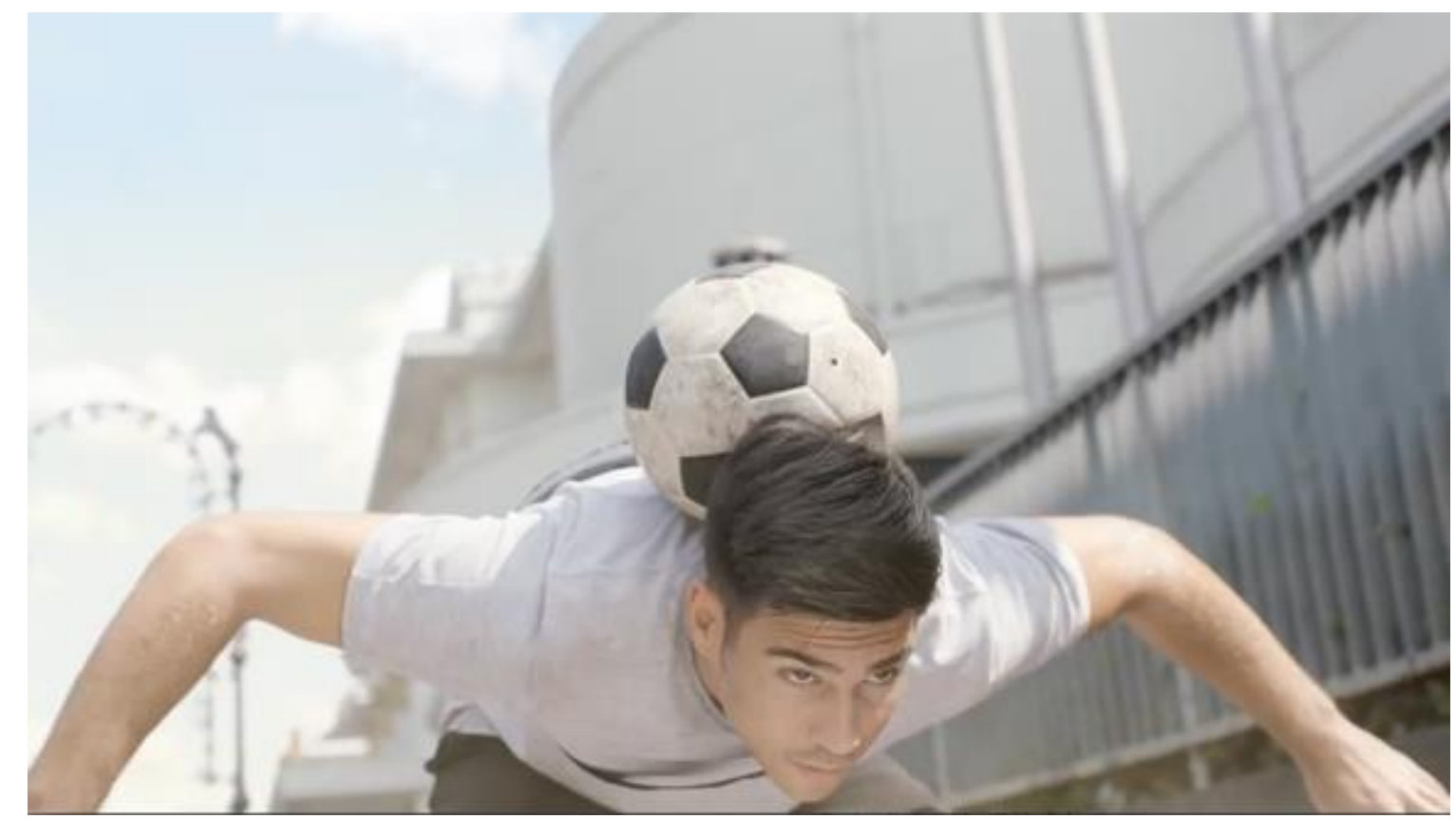

Gambar 8, 9, dan 10 Adegan 'Pria Menggiring Bola'

Table 4. Peta Bekerjanya Tanda Pada Adegan ‘Pria Menggiring Bola' Pada Iklan Men’s Biore Cool Oil Clear 2018 \#RefreshSemangatLo!

Penanda (Denotatif)

Gambar tiga orang pria bermain sepak bola di trotoar jalan

\section{Tanda (Denotatif)}

Sekelompok pria bekerja sama menggiring bola dengan berbagai gaya bebas di sepanjang trotoar jalan

\section{Tanda (Konotasi)}

Kerja sama dalam menuju suatu tujuan

\section{Mitos}

Pria adalah pemimpin
Petanda (Denotatif)

Tiga orang pria bermain sepak bola di trotoar jalan

\section{Mitos Pria Sebagai Pemimpin}

Dalam adegan Men's Biore Cool Oil Clear 2018 versi \#refreshSemangatLo!, mitos pria maskulin yang ditonjolkan, yaitu pria sebagai seorang pemimpin. Dalam potongan gambar, terlihat adegan tiga orang pria yang sedang menggiring bola dalam setting atau latar trotoar jalan di siang hari. Tiga orang pria tersebut juga melakukan teknik bermain bola dalam gaya bebas sambil melakukan opermengoper bola. Tiga orang pria yang melakukan free styling mengenakan wardrobe dengan konsep sporty yakni setelah kaos, celana pendek, juga sepatu sport.

Sifat maskulinitas yang nampak pada representasi pria sebagai pemimpin adalah Give em Hell dengan menunjukkan keberaniannya sebagai seorang pria yang melakukan hal tidak biasa dengan melakkan free styling di trotoar jalan, dalam situasi panas dan terik, serta dibalut denga debu dan asap dari kendaraan yang melintas disekitar jalan. Sekelompok pria dalam adegan ini mampu mengambil 
risiko untuk dapat mencapai tujuan. Sebagai seorang pemimpin pria wajib menunjukkan keberanian dan aura agresi.

\section{Dalam iklan Men's Biore Cool Oil} Clear 2018 \#RefreshSemangatLo!, aktifitas yang dipilih dalam adegan adalah bermain bola. Dimana sepak bola merupakan olah raga yang banyak digemari dan dimainkan oleh kaum adam. Dalam laman maxmanroe.com mengenai Permainan Sepak Bola: Pengertian, Sejarah, Teknik, Dan Peraturan Sepak Bola, salah satunya adalah (Muhadjir, 2000) sepak bola merupakan permainan dengan cara menyepak untuk satu tujuan yaitu mamasukkan bola ke gawang lawan dan berupaya membuat pertahanan agar bola tidak masuk ke gawang oleh lawan.
Permainan yang dijadikan olahraga ini memiliki sejumlah teknik seperti menendang bola, menghentikan bola, menggiring bola, menyundul bola, dimana tujuannya adalah mendorong dan mengarahkan bola pada gawang lawan untuk dapat mencetak gol.

Ningtriasih (2018) dengan merujuk pada studi yang dilakukan oleh neuro ilmiah mengungkap perbedaan cara berpikir pria dengan wanita, yakni dalam hal komunikasi pria cenderung lebih to the point, hal ini memberikan kesan pada pria talk less do more yakni sikap sedikit berbicara banyak bekerja, meski kerap dianggap membingungkan namun hal ini cukup efektif bagi pemimpin dan menunjukkan kewibawaan seorang pria.

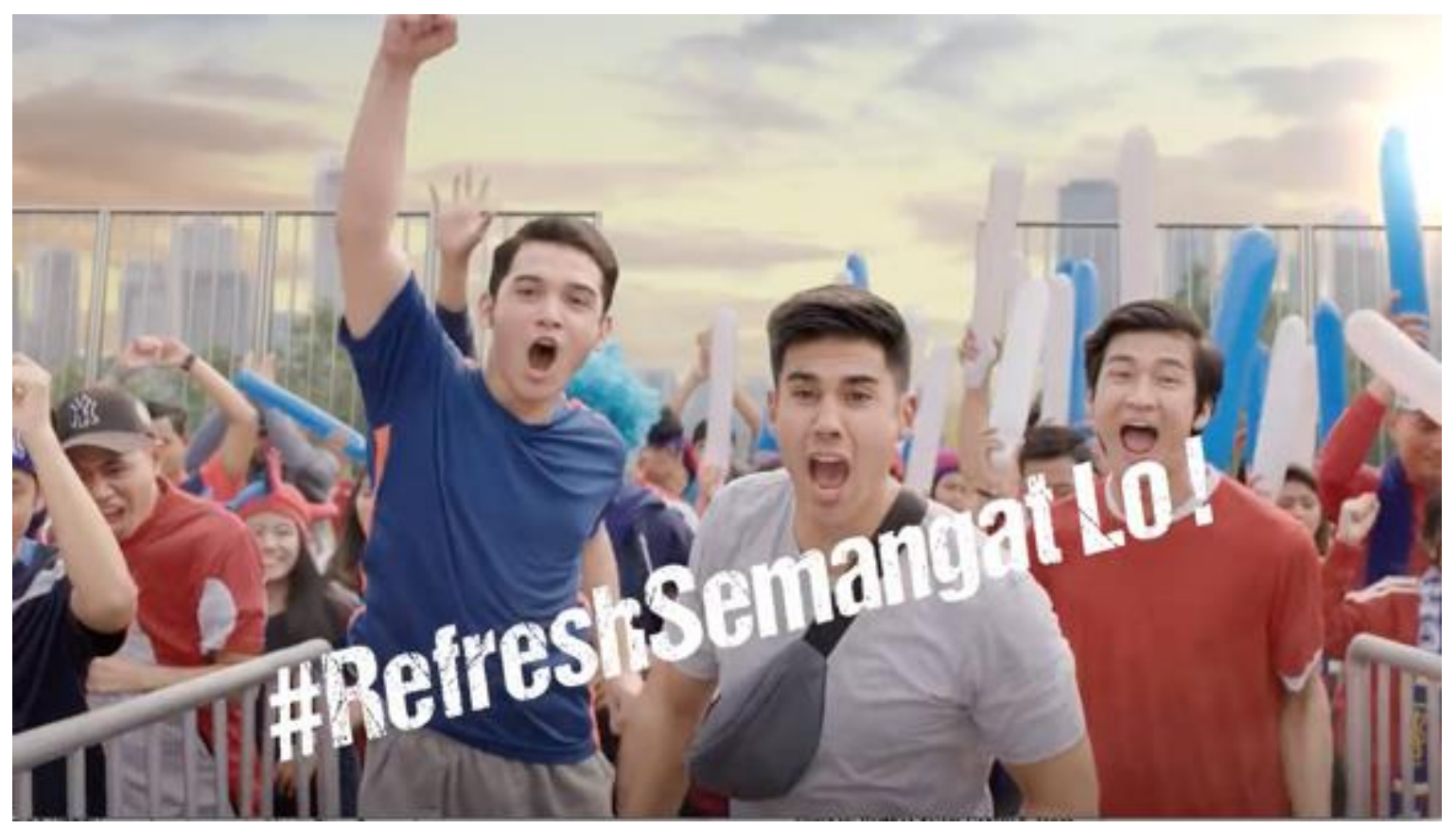




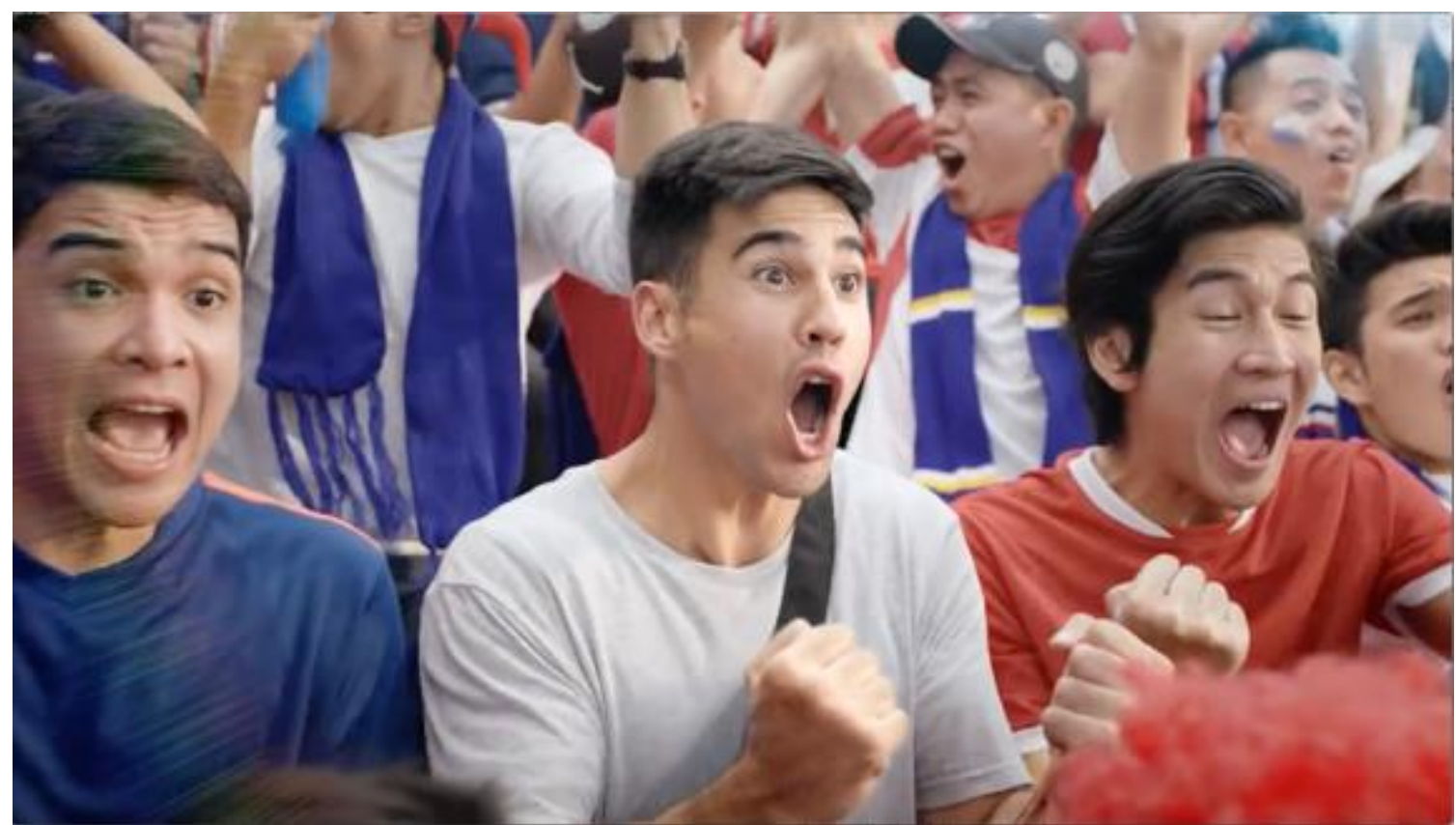

Gambar 11 dan 12. Adegan 'Pria Supporter Klub Sepak Bola'

Table 5. Peta Bekerjanya Tanda Pada Adegan 'Pria Supporter Klub Sepak Bola' Pada Iklan Men's Biore Cool Oil Clear 2018 \#RefreshSemangatLo!

\section{Penanda (Denotatif)}

Gambar sekelompok pria menjadi supporter klub sepak bola

\section{Petanda (Denotatif)}

Sekelompok pria menjadi supporter klub sepak bola

\section{Tanda (Denotatif)}

Sekelompok pria berbondong-bondong memeriahkan arena pertandingan untuk menjadi supporter klub sepak bola

\section{Tanda (Konotasi)}

Bersemangat dalam memberikan dukungan

\section{Mitos}

Pria adalah makhluk optimis

\section{Mitos Pria Sebagai Makhluk Optimis}

Dalam peta bekerjanya tanda pada adegan "Pria Supporter Bola", tergambar sekelompok pria yang sedang menjadi supporter atau tim pendukung klub sepak bola. Terlihat pula sekelompok pria itu dikelilingi oleh pria lainnya dengan atribusi supporter klub sepak bola. Latar yang tergambar adalah di stadion olahraga yang biasa digunakan untuk pertandingan sepak bola, dan kelompok pria itu duduk pada tribun atau tempat menonton bagi supporter pada siang hari yang terlihat cukup terik dalam suasana sorak sorai memberi dukungan. Pada adegan ini mitos yang terbentuk adalah pria sebagai makhluk optimis.

Dalam KBBI, optimis merupakan orang dengan pandangan baik dalam menghadapi berbagai hal. Sifat maskulinitas yang terbentuk pada mitos pria sebagai makhluk optimis adalah $B e$ a Sturdy Oak. Seperti dipaparkan oleh David dan Brannon, Be a Sturdy Oak bukan 
hanya menunjukkan bagi pria yang memiliki kekuatan saja, namun pria dengan rasionalitas, tidak menunjukkan emosi dan antusias dalam berbagai situasi.

Scheier et al., (2000) menyebutkan bahwa optimisme merupakan kepercayaan yang ditamankan pada suatu hal bahwa hal yang baik akan terjadi dimasa mendatang. Shapiro (2003) menjelaskan bahwa optimisma adalah sebuah kebiasaan yang dibangun oleh diri manusia dalam berpikir positif.
Hal ini sejalan dengan tujuan Komunikator iklan membuat iklan Men's Biore Cool Oil Clear 2018 \#RefreshSemangatLo dengan makna menyerukan kampanye bagi pria khususnya anak muda untuk memiliki jiwa sportif, fair, dan mampu memberikan dukungan kepada sesamanya agar mampu mendapatkan hasil terbaik. Pria maskulin sebagai makhluk optimis memiliki rasa patriotisme dan sepenangungan bersama dengan masyarakat yang menjadi pendukung/supporter suatu tim sepakbola.
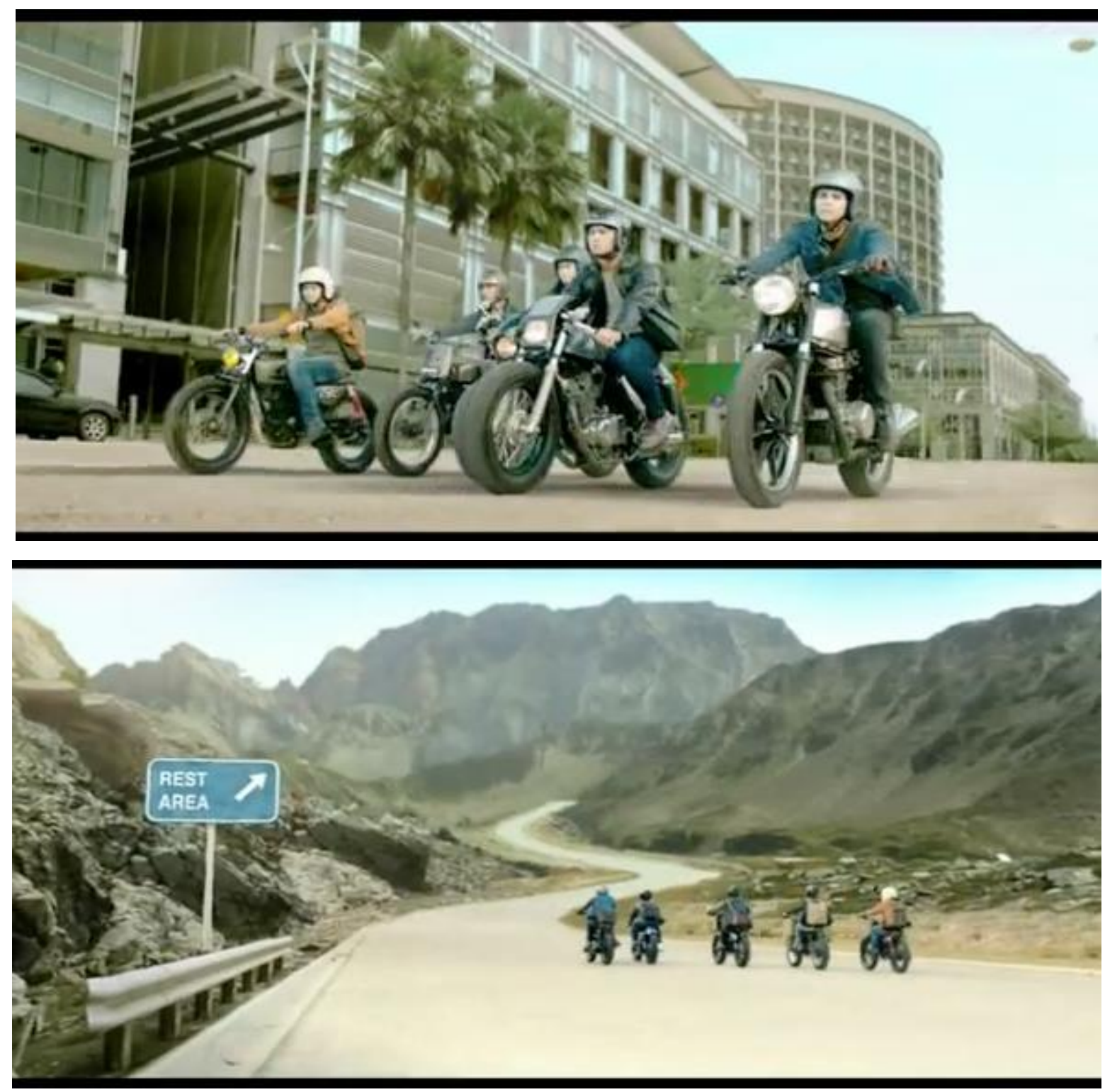

Gambar 13 dan 14 Adegan 'Pria Bermotor' 
Table. 6 Peta Bekerjanya Tanda Pada Adegan 'Pria Bermotor' Pada Iklan Men’s Biore Cool Oil Clear 2017 Versi Ride Along

\begin{tabular}{|c|c|}
\hline $\begin{array}{l}\text { Penanda (Denotatif) } \\
\text { Gambar sekelompok pria mengendarai } \\
\text { motor jenis custom motor }\end{array}$ & $\begin{array}{l}\text { Petanda (Denotatif) } \\
\text { Sekelompok pria mengendarai motor jenis } \\
\text { custom motor }\end{array}$ \\
\hline \multicolumn{2}{|c|}{$\begin{array}{l}\text { Tanda (Denotatif) } \\
\text { ekelompok pria mengendarai sepeda motor dengan jenis custom motor yang bervariasi } \\
\text { melintasi jalan besar yang dikelilingi bukit }\end{array}$} \\
\hline \multicolumn{2}{|c|}{$\begin{array}{l}\text { Tanda (Konotasi) } \\
\text { Keberanian untuk menguasai diri }\end{array}$} \\
\hline Pria adalah $\mathrm{m}$ & hluk penguasa \\
\hline
\end{tabular}

\section{Mitos Pria Sebagai Makhluk Gagah Berani}

Kegiatan mengendarai motor custom secara bergerombol biasa disebut dengan Sunmori (Sunday monring riding). Sunmori biasa dilakukan pada hari minggu pagi, berkumpul dengan sesama pecinta motor custom (biasanya dilakukan oleh komunitas), menelusuri suatu tempat dengan berkendara motor baik dalam kota hingga luar kota (long riding), dalam kegitaan ini biasa dimanfaatkan pecinta motor untuk berkomunikasi dan bercakap - cakap membahas segala hal.

Dalam adegan di atas, objek motor yang dipergunakan adalah motor custom dengan berbagai model dan karakter. Motor custom adalah motor yang telah melalui proses perubahan secara bentuk dan spek dari tiap bagian motor yang disesuaikan dengan keinginan si pemilik mulai dari rangka, stang, ban hingga bodi motor sehingga hasil akhirnya akan sangat berbeda dengan wujud aslinya. Berbeda dengan motor modifikasi yang bentuk atau wujud aslinya masih terlihat meski ditemukan beberapa perbedaan pada beberapa bagian. Jenis - jenis aliran motor custom yakni japstyle, tracker, tiger, café racer, bobber, scrambler, chopper dan lain sebagainya.

Sifat maskulinitas dalam mitos pria sebagai penguasa adalah Be a Big Wheel, dimana dalam hal ini maskulinitas seorang pria diukur dari bagaimana kesuksesannya, bagaimana ia menguasai diri dan dunia, dikagumi, dan bagaimana kekayaan yang dimilikinya. Penggambaran pria dengan mengenakan manly stuff seperti motor custom, pakaian rapi dan manly, dianggap sebagai pria dengan capaian kesuksesan, serta penggambaran melintasi jalan besar berbukit dengan motor merupakan hal ekstrim untuk melampiaskan hobi berkendara dengan motor dianggap sebagai kemampuan pria dalam menguasai diri dan menaklukan dunia. 

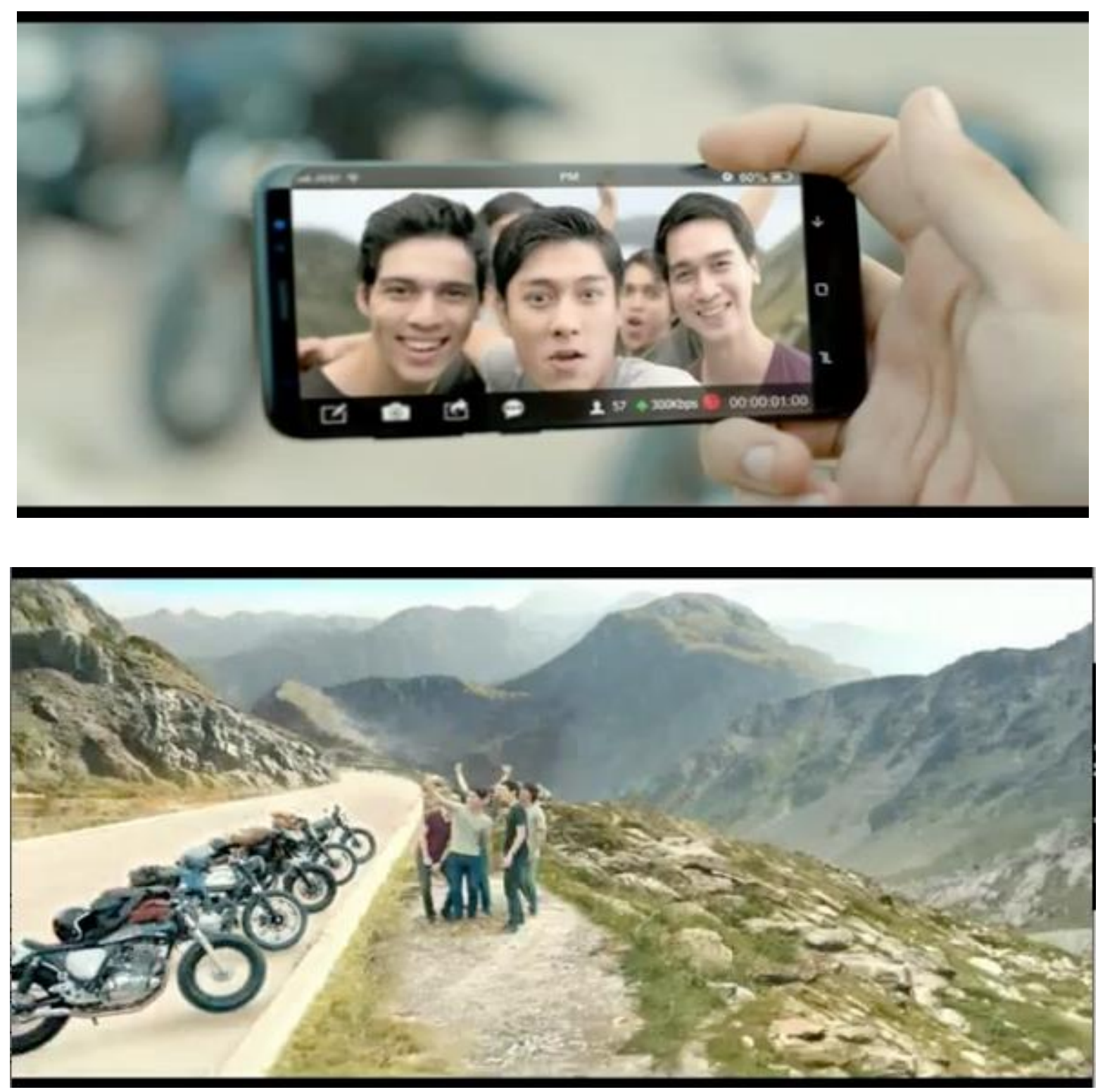

Gambar 15 dan 16. Adegan 'Pria Berswafoto'

Table. 7 Peta Bekerjanya Tanda Pada Adegan 'Pria Berswafoto' Pada Iklan Men's Biore Cool Oil Clear 2017 Versi Ride Along

\begin{tabular}{cc}
\hline Penanda (Denotatif) & Petanda (Denotatif) \\
Gambar sekelompok pria berswafoto & Sekelompok pria berswafoto \\
Tanda (Denotatif) \\
Sekelompok pria melakukan swafoto menggunakan telepon pintar dengan latar \\
perbukitan \\
Tanda (Konotasi) \\
Kebersamaan dan keindahan alam \\
Mitos \\
Pria makhluk narcissist
\end{tabular}




\section{Mitos Pria Sebagai makhluk narcissist}

Dalam adegan "Pria berswafoto", tergambar sekelompok pria berkendara dengan motor custom yang akan menuju tempat indah yang dipenuhi oleh bukit dan jalan yang lebar. Keindahan alam yang ditonjolkan merupakan tujuan dari kegiatan berkendara sekelompok pria bermotor ini.

Sekelompok pria tersebut kemudian mengabadikan momen capaian mereka dengan berswafoto (selfie), dan menunjukkan ekspresi kegembiraan dan kepuasan akan capaian yang telah dicapainya tersebut. Ini adalah ekspresi yang sangat wajar ketika seseorang mampu mecapai tujuan dan melampaui batas. Ekspresi tersebut adalah ekspresi kebanggaan.

Swafoto atau selfie merupakan kegiatan foto yang jenis pengambilan gambarnya diambil sendiri dengan menggunakan kamera depan ponsel, fokus objek pada diri sendiri. Penelitian yang dilakukan oleh Ardiyanti (2018) dalam Agustina \& Yongkie, (2019) fenomena swafoto menjadi daya tarik dalam berbagai bidang seperti psikologi, manajemen, budaya dan sebagainya.

Mitos yang dibentuk dari iklan ini, yakni pria sebagai makhluk narcissist. Beynon (2007) menjelaskan bahwa sifat maskulinitas New man as Narcissist tergambar dengan dirinya yang bergaya parlente atau manly. New man as Narcissist juga menggambarkan betapa pria tersebut mencintai dirinya dengan mengapresiasi diri pada barang-barang mahal seperti kendaraan mewah, rumah, pakaian yang mendeskripsikan dirinya sebagai pria yang sukses.

\section{KESIMPULAN}

Penulis telah melakukan
pengolahan data dengan cara
mengkategorikan berdasarkan peta
bekerjanya tanda Roland Barthes baik
konotatif dan denotatif pada iklan Men's
Biore. Pada peta Bekerjanya Tanda.
Kemudian menghasilkan konstruksi dari
ide tentang karakteristik maskulinitas yang
terdapat dalam iklan Men's Biore Cool Oil
Clear dalam tiga versi yakni \#BeMagnetic
2019, \#RefreshSemangatlo! 2018 dan versi
Long Riding 2017. Dari ketiga versi iklan
ini, citra maskulinitas yang mengacu pada
Beynon dalam bukunya berjudul
Masculinities And Culture, yakni terdapat
tiga kategori yakni, maskulin sebelum
tahun 1980-an, maskulin tahun 1980-an,
dan maskulin tahun 20oo-an.

Ketiga iklan produk Men's Biore memiliki tujuh mitos representasi maskulinitas yang berbeda dan beragam pada pria, yakni pria sebagai makhluk bebas, pria sebagai makhluk rupawan, pria sebagai makhluk kharismatik, pria sebagai pemimpin, pria sebagai makhluk optimis, pria sebagai makhluk penguasa, dan pria sebagai makhluk narcissist.

Komunikator iklan membuat iklan dengan pesan yang ingin disampaikan kepada konsumen bahwa kebersihan wajah bisa dibentuk dengan cara mudah yakni mencuci muka. Dengan demikian maka harapan yang dibangun adalah membuat representasi maskulinitas pria yang disesuaikan dengan tren yang kini sedang berlangsung dan digandrungi kaum pria. Pada ketiga versi iklan ini memberikan gambaran bahwa pria maskulin pada dasarnya adalah pria yang memperhatikan kebersihan dan penampilan diri sendiri, yang membuka sudut pandang baru di masyarakat luas atas stereotype imaji maskulin yang selama ini beredar. 


\section{Daftar Pustaka}

Adam, A. (2017, Agustus 17). Ledakan Industri Kecantikan Pria. Retrieved from https://tirto.id/: https://tirto.id/ledakan-industrikecantikan-pria-cuZc

Agustina, I. A., \& Yongkie, A. (2019). Fenomena Swafoto Dan Pengaruhnya Terhadap Budaya Visual Pada Estetika Interior Ruang Komersial. Jurnal Desain Interior, 4(1).

Asrofah. (2014). Semiotic mitos roland barthes dalam analisis iklan di media massa. Jurnal Sasindo, 2(1).

Bungin, B. (2011). Konstruksi Sosial Media Massa: Kekuatan Pengaruh Media Massa, Iklan Televisi, Dan Keputusan Konsumen Serta Kritik Terhadap Peter. L Berger \& Thomas Luckmann. Kencana.

Flocker, M. (2003). Metrosexual Guide To Style. Da Capo Press Cambridge.

Ibrahim, I. S. (2007). Budaya Populer Sebagai Komunikasi Dinamika Popscape Dan Mediascape Di Indonesia Kotemporer. Jalasutra.

Iskandar, A. A. (2018). Pentingnya Memelihara Kebersihan Dan Keamanan Lingkkungan Secara Partisipatif Demi Meningkatkan Gotong Royong Dan Kualitas Hidup Warga. Jurnal Ilmiah Pena, 1(1).

Jannah, L., \& Kusumawati, D. (2016). Maskulinitas Dalam Iklan Produk Perawatan Wajah Untuk Laki-Laki (Analisis Wacana Maskulinitas Dalam Iklan Garnier Men Versi Two Men's World, Versi Urban Hero Dan Versi Joe Taslim). Jurnal Kommas UNSFak. ISIP.
Kartajaya, H. (2006). Marketing In Venus. PT. Gramedia Pustaka Utama.

Kusumaningrum, E. (2012). Maskulinitas Dalam Iklan Majakan Men's Health. Universitas Sebelas Maret.

"Ledakan Industri Kecantikan Pria." (n.d.). Tirto.Id. Retrieved February 28, 2020, from https://tirto.id/ledakan-industrikecantikan-pria-cuZc

Lippke, S., \& Renneberg, B. (2006). Theorien und Modelle des Gesundheitsverhaltens (pp. 35-60). https://doi.org/10.1007/978-3-54047632-0_5

Muhadjir, N. (2000). Metodologi Penelitian Kualitatif. Rake Sarasin.

Ningtriasih. (2018, Maret 05). Ini Perbedaan Cara Berpikir Laki-laki dan Perempuan. Retrieved from Medcom.com:

https://www.medcom.id/rona/keseh atan/yKXVaM6b-ini-perbedaancara-berpikir-laki-laki-danperempuan

Rahardjo, M. (2018). Paradigma Interpretatif. Repository.UinMalang. Repository.uinmalang.ac.id/2437.

Rahayu, N. U., \& Afrianto, D. T. (2017). Representasi Citra Laki - Laki Dalam Iklan Gatsby Styling Pomade Kajian Semiotika Roland Barthes. Jurnal Seni Media Rekam Capture, 9(1).

Runtiko, A. G. (2011). Konstruksi Budaya Maskulin Daam Iklan. Jurnal Penelitian Komunikasi, 14(1), 63-80.

Rusmana, D. (2014). Filsafat Semiotika. CV Pustaka Setia. 
Savitri, D. (2011, April 18). 10 Syarat Jadi Pria Maskulin. Retrieved from http://health.kompas.com: https://sains.kompas.com/read/2 011/04/18/10023096/10.syarat.ja di.pria.maskulin

Scheier, M. F., Carver, C. S., \& Bridges, M. W. (2000). . Optimism \& Pessimism: Implications For Theory, Research and practice. American Psycological Association.

Tanjung, S. (2012). Maskulinitas Pada Majalah Cosmopolitan Indonesia. Jurnal Komunikasi UII, 6(2).

"Tren Pasar Perawatan Tubuh Pria." (n.d.). Retrieved February 27, 2020, from

https://indonesiaimaji.com/trenpasar-perawatan-tubuh-pria/

Triwidiastuty, S., \& Kahija, Y. F. La. (2015). Memahami Makna Menjadi Laki-Laki Metroseksual. Jurnal Empati, 4(2), 58-64.

Wajcman, J. (2001). Gender and technology. In N. S. James D Wirght, nternational encyclopedia of the social \& behavioral sciences (volume 9) (pp. 5976-5979). Amsterdam-New York: Elsevier
Wen, T. (2017, November 3). Cara menguasai seni dan teknik agar menjadi sosok karismatik.

Retrieved from bbc.com: https://www.bbc.com/indonesia/v ert-cap-41843105

Wibowo, \& Wahyu, I. S. (2011). Semiotika Komunikasi. Mitra Wacana Media.

Yuliyanti, F. D., Bajari, A., \& Mulyana, S. (2017). Representasi Maskulinitas Dalam Iklan Televisi Pond's Men \#Lelakimasakini (Analisis Semiotika Roland Bartes Terhadap Representasi Maskulinitas). Jurnal Komunikasi UII, 9(1), 16-30.

"1o Arti Warna Dalam Psikologi Warna, Terpopuer Menurut Para Ahli!”. (n.d.). Goodminds.Id. Retrieved March 9, 2020, from https://goodminds.id/arti-warna 